\title{
Anatole France no Divã
}

Milene Suzano de Almeida*

"Anatole France, père de la psychanalyse!" (Anatole France, pai da psicanálise!). Essa é a tarja externa que acompanha o livro de contos e crônicas intitulado Les fous dans la littérature (Os loucos na literatura), cujo tema é, segundo o prefaciador Georges Londeix, "Anatole France visto pelo ângulo dos fundadores da psicanálise" (FRANCE, 1993, p. 08). Logo nas primeiras palavras de Londeix, sabemos que o autor preferido daquele que é realmente conhecido como o pai da psicanálise, Sigmund Freud, foi Anatole France. O texto que aparece nas próximas páginas, "Balzac, príncipe do mal" (FRANCE, 1993, pp. 59-64), integra a coletânea de artigoos e crônicas contidos no volume dos loucos, mas foi publiçado anteriormente no jornal Le Temps, de 29 de maio de 1887, e reproduzido em 1888 no primeiro volume da série Vie littérairel:

Quanto à relação entre Freud e France, em 1907, con̉vidado a designar dez bons livros, o verdadeiro pai da psicanálise cita o último romance de France, Sur la pierre blanche, de 1905 e, em 1909 , envia ao amigo Sándor Ferenczi alguns livros deste mesmo autor. Ferenczi publica em 1911 um artigo intitulado "Anatole France, psicanalista", texto apoiado nas obras do escritor francês que vieram a público entre 1887 e 1897, nas quais, segundo Ferenczi, France atribui aos heróis suas próprias observações psicợógicas, "no discurso suave do abade Coignard sempre pronto.a compreender e a perdoar, nas reflexões penetrantes do Senhor $r$ Bergeret e em outros momentos" (FRANCE, 1993, p. 08).

Relação a princípio inesperada, se pensarmos em France como um autor fortemente criticado pelos surrealistas - no senso comum, os verdadeiros representantes da vida psíquica na arte. É importante ressaltar que a explicação de Londeix para a afinidade entre Freud e France toca na contínua tensão entre o recurso às fontes clássicas e a interpretação da realidade em que vivem. Enquanto Freud recorre às fontes gregas para tratar da mente humana em seu tempo, France mescla constantemente os tempos mais remotos e a realidade mais imediata.

Na pequena crônica sobre Balzac, é possível ver nas mãos de Lady Macbeth, nas referências bíblicas, na escultura do século XVII ou
Mestre em Teoria

e História Literária pela Universidade de Campinas (Unicamp) e doutoranda no Departamento de Letras Modernas (DLM) da Universidade de São Paulo (USP). E-mail: milenesuzano@usp.br.

INèste volume, o título da crônica é somente "Balzac" e é escrito como comentário ao livró Répertoire de La Comédie humaine de M. Anatole Cerfberr e Jules Christophe. Há aí a continuação da crônica, que trata mais especificamente do Répertoire, um resumo dos doois mill personågens da Comédia Humana. Nesta edição de La vie littéraire, encontra-se também a resposta de Cerfberr e Christophe. Ver FRANCE, Anatole. La vie littéraire I. Paris: Calmann-Lévy éditeurs, 1925 
na imprevisibilidade de Fuegiens ou Boschimans - referências a povos ditos então primitivos -, traços dessa relação que se repete em contos e romances. Essa retomada de textos ou elementos remotos ou exóticos não só liga France a Freud, como faz pensar também na tradição enciclopédica das letras francesas, assim como pode remeter, de forma mais atual, a Jorge Luis Borges, que coloca em questão a própria ideia de autoria, pensando a ficção não como uma existência particular, mas como ficção dentro de ficções, livros dentro de livros.

Desse enciclopedismo deriva outra característica de France que diz respeito à sua concepção da história e da literatura. MarieClaire Bancquart, organizadora dos quatro volumes das obras selecionadas de France e especialista no autor, afirma, ao tratar do romance histórico Les Dieux ont soif (1912), que desde Le crime de Sylvestre Bonnard (1881) France compreende a história como uma reunião de escolhas subjetivas. Não há uma oposição entre fatos históricos e não-históricos, já que para ele o ato de simplificar e abstrair é um afastamento do vivido. Portanto, as fronteiras entre o ficcional e o histórico parecem-lhe tênues. Na crônica traduzida nas próximas páginas, essa instabilidade entre realidade e ficção aparece nas referências ao louco, quando, por exemplo, ele pergunta ao narrador: "O senhor não leu a verdadeira história daquele homem enlouquecido por La Gioconda, de Leonardo, que, um dia, ao sair do Salon carré, jogou-se no Sena?" Existe esta história? Ela é verdadeira? De fato, com France, saber se é ou não real, não importa. O prazer da literatura é deixar-se levar pela imaginação.

Sendo o texto a seguir parte de um volume dedicado ao France psicanalista e pensando o narrador ao mesmo tempo como arialista e analisado, gostaria de sugerir que esse enaltecimento do prazer é também uma proteção do autor diante de si mesmo. Talvez venha daí o apreço pelos loucos dos mais diversos matizes. O próprio Londeix sugere: "France buscou grandes prazeres. Preocupado.ern consonóar-se em primeiro lugar" (FRANCE, 1993, p. 20). A fråse final da primeira parte do conto Jeán Marteaux, tambémi incluído na coletâneả, trata desse medo do contato consigo mésmo na voz do narradơr: "Essa visão, por sí, pode incutir horror $^{\text {"I.2 }}$ (FRANCE, 1993, p. 115). Bancquart (1991) fala também de uma recusa do narrador, mesmo nas obras mais explicitamente autobiográficas, em revelar as feridas do passado. Tanto nas verdades alteradas como nos silêncios do narrador, esses espaçớs que se revelam no apreço pelos loucos são os mesmos que nos fazem perceber as contradições desse autor.

France certamente foi contraditório como homem e a a autor. Contradições sem síntese: um pessimista com bom humor, talvez. Muito conformista para uns, perigoso utopista para outros, somente um escritor de pastiche ainda para outros. Infelizmente, ficou marcado pelos primeiros. Mais do que escritor datado,

2A frase original "La vision de soi peut faire quelque horreur" aparece no primeiro ato, cena III da peça

Po̊lyeucte, de Pierre Cợneille, de 1643, nas palavras de Stratonice, confidente de Pauline, esposa de Polyeucte. $\mathrm{Na}$ peça, a frasse apårece com vírgulâs: "La vision, de soi, peut faire quelque horreur", mas a citação de France não as mantém. A tradução usada acima é de Jenny Klabin Segal. Ver Corneille, Pierre. O Cid; Horácio, Polieucto. São Paulo: Martins Fontes, 2005, p. 200. 
France foi esquecido, pois sua memória está ligada ao ódio dos surrealistas, cuja origem remonta à rejeição a Stéphane Mallarmé e Paul Valéry para integrar o terceiro volume da coletânea de poesias Parnasse Contémporain em 1875. Esta memória se explicita no panfleto de 1924, data da morte de France, no qual os surrealistas se referem ao "cadavre" France e comemoram o falecimento daquele que representava para eles o tradicionalismo e a servidão humana. Curiosamente, o manifesto oscila entre dois polos: France e Freud. Ao primeiro, a crítica: "festejemos o dia em que o enterramos..."(FRANCE, 1993, p. 11); ao outro, o entusiasmo: "Graças às descobertas de Freud, [...] a imaginação está talvez a ponto de recuperar seus direitos" (FRANCE, 1993, p. 11). Grande ironia, se lembrarmos que a imaginação era a grande apologia de Anatole France, ideálizada no início da carreira é mais amargurada ao final. Sem ésquecer também que France era apreciado por Freud. Talvez teñha sido a clareza da escrita anatoliana que, suprimindo o mistério tão caro aos surrealistas, ou mesmo o rancor, os tenha levado a essa interpretação. O contraditório Frảnce, o dreyfusard, o sensưalista, o autor consagrado, o anticleriçal convičcto, o socialista, o pessimista, ensejava dúvidas. Pois ele foi tudo ìsso, e é o que o torna ainda instigante. É preciso reconfecer isso nele. Do outro lado dos seus próprios silêncios, France reserva humanidade àqueles 'que analisa em suas obras. Seu ceticismo, sua ironia e sua piedade $\mathrm{O}$. permitem. $\mathrm{Na}$ leitura que faz do conto Crainquebille?, Joseph Conrad define France como um "analista de ilusões": "Elè é ưm granno de analista de ilusões. Ele procura e examina seus recantos mais íntimos como se fossem feitas de uma substância eterna. E é aí que reside sua humånidade" (CONRAD, 2010, p. 30). De fato, reserva para si o silêncio, e, para as pérsonagens e situações que narra, tem um olhar arguto de observador. Quase um analista no sentido psicanalítico. No seu estilo claro e límpido e como num processo terapêutico, France fala de seus loucos com piedade e com uma quase identificação. Afinal, que visão não tem o louco do conto aqui traduzido quando diz que os mais inocentes dos personagens ficcionais desviam nossa ternura para seres imaginários enquanto que os seres humanos ficam à deriva? France que, como analisado, encobriu seus próprios medos, dando-Ihes uma forma artística, como analista, reserva aos mais fracos - aqui os loucos - a sua piedade, mas é mordaz na ironia em relação aos tiranos e aos injustos.

Pensando France como um analista, também aqui nesta pequena introdução, busquei fazer uma espécie de processo terapêutico, desvendando o escritor a partir de uma pequena parte de sua obra, em que pequenos atos falhos deram ensejo a interpretações que ultrapassam o escopo do texto a seguir. Busquei traços do autor, pois seria impossível resumi-lo, já que são exatamente as suas contradições que o mantêm atual e estimulante.
3 Conto publicado no volume III das obras completas de Anatole France, na coletânea . intitulada "Crainqůẻille, Puitoiois, Riquet et plusieurs autres récits profitables". Ver FRANCE, Anatole. Oeuvres III. Édition établie, présentée et annotée par Marie-Claire Bancquart. Paris: Éditions Gallimard, 1991, pp. 721745. No Brasil, há uma tradução da coletânea de 1978 por João Guilherme Link, cujo título é "A justiça dos homens". 


\section{alzac, príncipe do mal 4}

Estava um dia procurando livros num sebo do quartier latin, quando observei num canto da loja um homem de cábelos longos, jovem ainda, que parecia ter um caráter expanisivó, Sua figura me era conhecida sem que me fosse possível atribuir-lhe um nome. Ele folheava um livro; seu olhar, seu sớriso, as rugas móveis de seu rosto, seus gestos amplos, tudó falava por ele antes mesmo que ele encontrasse um interlocutor. Não é necessário muito instinto para pressentir um falador. Senti que ou fugia ou tornar-me-ia sua presa. No entanto, fiquei. Sófocles tinha razão ao dizer que ninguém pode evitar seu destino. Passei por muitas provas disso em minha vida. Não sei resistir à má nem à boa sorte. Porém, a má é naturalmente a mais frequente. Na verdade, esse frequentador de sebos não me era antipático. Ele possuía aquela fisionomia alegre, aquele ar à vontade dos pobres que não sentem sua pobreza e dos preguiçosos que sonham sem parar. Suas roupas, mais descuidadas que sujas, pareciam-me empoeiradas com o nobre pó das bibliotecas. Ele as trajava sem preocupação e sem interesse. Somente o chapéu, cujas abas eram estranhamente largas e a seda eriçada, revelava um gosto, um caráter, talvez até mesmo uma estética. Vivendo apenas da mente, sem dúvida, esse homem só se incomodava em trajar sua cabeça. As outras vestes não Ihe interessavam. Lamento dizer que ele tinha as mãos sujas. Mas sabemos pela tradição que o príncipe dos bibliotecários, o velho Weiss, de Besançon, revelava semelhante negligência. Ocorria com as suas mãos o mesmo que se dava com as de Lady Macbeth. Continuavam escuras após o banho, e o Sr. Weiss explicava-se dizendo que lia em sua banheira.

O homem, tão logo me viu, avançou em minha direção, batendo no livro:

- Leia, disse-me. É a lei santa, a lei do Senhrơor.

Ele carregava uma velha bíblia de Sacyớ, aberta no "çapítulo XX do Êxodo, e seu dedo me indicava o verso 4: "Não farăs imagem esculpida."

- A humanidade, acrescentou, perecérá na loưucura por tẻrtransgredido esse mandamento.

Vi que estava lidando com um louco. Não me incomodei com isso. Os loucos são algumaś vèzes divertidos. Não ous'o dizer que eles raciocinam melhor que os outros homens, mas eles'o fazem de outra maneira, e é prieciso reconhịecer isso neles. Eu não temia contrariá-lo um pouco:?

- Desculpe-me, disse-the, eu sou idólatra e adoro as imagens.

- E eu, respondeu-me, àmei-as loucamente. Mil mortes por elas sofri. Por isso detesto-as é as tenho por diabólicas. O senho não leu a verdadeira história daqúele homem enlouquecido por $\mathrm{L} a \mathrm{Gi}$ oconda, de Leonardo, que, um dia, ao sair do Salon carréé, jogouse no Sena? Não se recorda do que disse Luciano de Samósata
4 FRANCE, Anatole. "Balzac, le prince du mal". In FRANCE, Anatole. Les fous dans la littérature. Édition présentée par Georges Londeix. Paris: Le Castor Astral, éditeur, 1993. Texto publicado̊ o̊riginalmente sob o título "Balzac", no primeiro volume de $L a$ Vie Littéraire.

Tradução da bíblia de . Łouis-Isaac Lemaistre de Sacy, muito difundida na França do século XVIII.

(G) O Salão do Louvre foi, no século XIII, um dos mais prestigiosos do museu. O quadro de Leonardo da Vinci foi roubado do museu em 1911, sendo mais tarde recuperado. 
sobre um jovem grego a quem a Vênus de Cnide inspirou um amor sacrílego e funesto? Ignora que o mármore da Hermafrodita $7^{\circ}$ do Louvre foi gasto pelo toque das mãos dos visitantes, e que a administração dos muiseưus teve de proteger por uma barreira essa figurả monstruiosa e encantadorà? Éscapa-Ihe que os Cristos crucificădos e as Virgens pintadas são em toda a cristandade objetos da mais grosséira idolatria? É préciso dizer que, de maneira geral, os quadros e as estátuaias perturbam os sentidos, induzem o espírito ao erro, inspiram o fastio e o horror à realidade, e tornam os homens mil vezes mais infelizes do que foram na sua barbárie primitiva. São ơbrảs ímpiảias e abomináveis.

Opus-me timidamente alegando que, considérado o o todo, a parte da estatuária e da pintura é bem pequena nas perturbações da carne e do sangue que agitam os homens, e que a arte, ao contrário, arrebata seus amantes nas regiões mais serenas em que só experimentam prazeres tranquilos.

Meu interlocutor fechou sua pequena e velha Bíblia e prosseguiu sem se dignar a me responder:

- Existem imagens mil vezes mais funestas que as esculpidas e pintadas, das quais Jeová quis preservar Israel: são as imagens por excelência, as imagens ideais que os romancistas e poetas concebem. São os tipos e os temperamentos, são as personagens dos romances. Essas figuras levam uma vida ativa: elas têm almas; e é justo dizer que seus malignos autores as jogam entre nós como demônios, para nos tentar e nos perder. E como escapar delas, uma vez que habitam em nós e nos possuem? Goethe lança Werther no mundo: imediatamente os suicídios se multiplicam. Todos os poetas, todos os romancistas, sem exceção, perturbam a paz na terra. A llíada, de Homero e Germinal, de Zola, também criaram crimes. Émile transformou em terroristas e degoladores aqueles que Jean-Jacques queria trazer de volta à natureza. Os mais inocentes como Dickens são mesmo assim culpados; eles desviam nossa ternura e piedade para esses seres imaginários, sentimentos que seriam melhor investidos nos seres vivos que nos rodeiam. Tal romancista produziu histéricas; um outro, coquetes; um terceiro, jogadores ou assassinos. Mas o mais diabólico de todos, o Lúcifer da literatura, é Balzac. Ele imaginou todo um mundo infernal, que hoje concretizamos. É a partir de seus esquemas que somos ciumentos, gananciosos, violentos, injuriosos e que nos precipitamos uns sobre os outros pela conquista do ouro, no ataque às virtudes, com uma fúria homicida e ridícula. Balzac é o príncipe do mal e seu reino chegou. Por todos os escultores, por todos os pintores, por todos os poetas, por todos os romancistas que, desde os primórdios do mundo até este momento fizeram mal à humanidade, que Balzac seja amaldiçoado!

Ele parou para respirar:

- Que pena! disse-lhe, o que o senhor diz não está desprovido de razão (era conveniente lisonjeá-lo); mas os homens não
7.Trata-se de L'Hermaphrodite enidormie, esculpida por Gian Lorenzo Bernini no século XVII. 
tiveram que esperar os artistas para serem violentos e devassios: Átila e Gengis-Khan, que não leram Homero, foram guerreiros mais destruidores que Alexandre. Os Fuegians e os Boschimåns são depravados, e eles não sabem ler nem desenhar. Os camponeses assassinam seus velhos pais sem nenhuma reminiscência romanesca. A concorrência vital era assassina antes de Balzac. Já havia greves antes que Germinal fosse escrito. As artes inspiramIhe muita raiva e temo, senhor, que seja um moralista parcial.

Ele me cumprimentou com seu grande chapéu e disse:

- Eu não sou moralista, senhor; sou escultor, poeta e romancista. Quando ele se foi:

- É um homem que tem bastante espírito, senhor, disse-me o livreiro; mas ele não é feliz, e Balzac o fez perder a cabeça.

(fim)

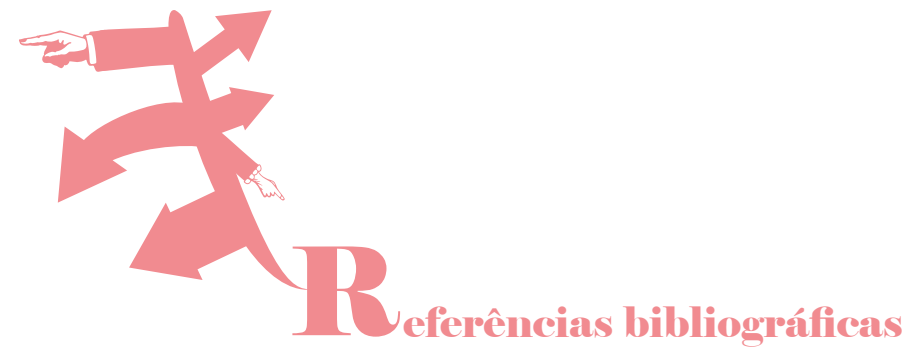

FRANCE, Anatole. Les fous dans la littérature. Édition présentée par Georges Londeix. Paris: Les Castor Astral, 1993.

BANCQUART, Marie-Claire. Notice. In.: France, Anatole. Oeuvres III. Éditions établie, présentée et annotée par Marie-Claire Bancquart. Paris : Éditions Gallimard, 1991.

CONRAD, Joseph. Notes on life and letters. England: General Books LLC, 2010. 